\title{
Normas jurídicas y subjetividades capitalistas. Los dispositivos del derecho laboral y la psicología*
}

\author{
Positive Law and Capitalist Subjectivity. \\ The apparatus of Labor Law and Psychology
}

Recibido: febrero 28 de 2013 | Revisado: julio 15 de 2013 | Aceptado: agosto 15 de 2013

OSCAR ANDRÉS LÓPEZ CORTÉS **

Pontificia Universidad Javeriana, Bogotá, Colombia

Doi: 10.11144/Javeriana.UPSY12-4.njsc

Para citar este artículo: López, O. A. (2013). Normas jurídicas y subjetividades capitalistas. Los dispositivos del derecho laboral y la psicología. Universitas Psychologica, 12(4), 1101-1111. Doi: 10.11144/ Javeriana.UPSY12-4.njsc

* Este artículo es producto de las reflexiones adelantadas al interior del Grupo Interinstitucional "Procesos de Regulación y Trabajo Contemporáneo”, conformado por miembros de las universidades Javeriana, Piloto y Sabana.

* Catedrático de la Facultad de Psicología de la Pontificia Universidad Javeriana, Bogotá. Research ID: M-3459-2013.E-mails: lopez-oscar@javeriana.edu. co; andreslopezc@yahoo.com

\section{RESUMEN}

Este artículo explora la relación entre derecho y psicología en el caso particular de la ley de teletrabajo en Colombia y los discursos sobre el sujeto trabajador de las TIC. Ley y discursos son tomados como líneas de un dispositivo legal y psicológico, mediante el cual se configura la subjetividad del teletrabajador entre el derecho y psicología, tomando ambas disciplinas como formaciones que constituyen y administran relaciones de poder ejercidas por los sujetos sobre sí mismos. En lo metodológico propongo un análisis genealógico de los discursos que integran el dispositivo por el cual se constituye la subjetividad en la forma de organización laboral conocida como teletrabajo.

\section{Palabras claves autor}

Subjetividad, teletrabajo, dispositivo, deseo, tecnología.

Palabras clave descriptores

Subjetividad, derecho, teletrabajo, dispositivo.

\section{A B S T R A C T}

To explore the relation among law and psychology in the particular case about telework's rule and speeches about e-worker is the main of this article. Law and speeches are taken as lines of a legal and psychological apparatus through are performed the e-worker subjectivity between both disciplines. I take both disciplines as knowledge formations that to constituted and manage power relationships exerted by subjects themselves. Methodologically I propose an genealogical analysis of speeches that to integrate the apparatus by which are performed the subjectivity in the frame of labor organization called telework.

Key words authors

Subjectivity, Telework, Apparatus, Desire, Technology.

Key words plus

Subjectivity, Law, Telework, Apparatus. 


\section{Introducción}

Sobre el origen de las leyes laborales se tejen diferentes narrativas; quizás quienes defienden su origen revolucionario como conquistas arrancadas al capital mediante luchas obreras, en el fondo no están lejos de quienes sostienen que las leyes son producto de la razón alcanzada tras circunstancias históricas vinculadas a la ampliación de la teoría de los derechos fundamentales. En otras orillas, persisten argumentos según los cuales las leyes sobre trabajo solo son instrumentos de dominación de clase propicias para el desenvolvimiento del capitalismo como forma económica dominante.

En las líneas que siguen se hará una aproximación a la ley colombiana sobre teletrabajo para argumentar que no es ni conquista ni instrumento de dominación; que en su lugar, es un dispositivo -en el sentido dado a esta expresión por Michel Foucault-mediante el cual se da forma a la subjetividad capitalista al interior de relaciones de poder. Esta aproximación implica dos aspectos traslapados: una apreciación de las prácticas discursivas del poder y a una psicología de las normas laborales.

En lo metodológico, se propondrá una exploración genealógica de los discursos más sutiles surgidos alrededor de la ley 1221, no las grandes narrativas, sino a los saberes locales, o lo que Foucault (2000) - a partir del trabajo de Deleuze-denominó discursos menores. La intención es reconstruir la ley a partir de sus objetivos implícitos, sus estrategias y los programas de acción política que promueve (Foucault, 2006). Dicha exploración no busca establecer la verdad, tan solo discutir otras eventuales condiciones de posibilidad de la norma y la manera como esta es incorporada por las personas a través de ciertas formaciones discursivas, como la planteada por una parte de la psicología organizacional que promueve en el sujeto la importancia del emprendimiento, la autogestión, el trabajo autónomo, entre otros "valores", que apuntan a formar la subjetividad del trabajador del ciberespacio. Se propone entonces una historia externa de la ley 1221, la que surge en las prácticas discursivas de la psicología y el derecho, donde nacen formas de subjetividad, dominios de objetos y tipos de saber (Foucault, 2001).
Como podrá advertirse, esta aproximación toma prestada herramientas conceptuales desarrolladas en distintos trabajos de Michel Foucault, por lo que será preciso comenzar la exploración precisando el alcance de expresiones como dispositivo, práctica discursiva, mecanismos de sujeción, régimen de veridicción y aproximación genealógica en Foucault. Enseguida, y con un marco teórico brevemente expuesto, se intentará hacer una lectura crítica de la ley sobre teletrabajo y la manera como sus dispositivos intervienen quirúrgicamente las subjetividades capitalistas mediante la producción de identidades, roles, estereotipos, deseos, gustos y estéticas, desarrolladas en las prácticas y las relaciones de trabajo propias del entorno en el que las tecnologías de la información y las comunicaciones (en adelante las TIC) son tanto herramientas de producción como objetos de consumo (Huws, 2003).

\section{El derecho como régimen de veridicción}

En diferentes partes de su obra Foucault desarrolló el concepto de dispositivo, mediante el cual analizó las formas como el poder fluye a través de los cuerpos y de las instituciones, así como la manera mediante la cual distintos regímenes de veridicción se articulan a la relación saber-poder. La relación entre dispositivos y regímenes de veridicción es estrecha y mutuamente constitutiva. Los dispositivos se manifiestan tanto en la forma de vectores discursivos como de instituciones físicas concretas en las cuales las prácticas discursivas toman forma. El dispositivo saber-poder es definido por Foucault como el "acoplamiento serie de prácticas-régimen de verdad" mediante el cual es posible hacer que algo inexistente se convierta en algo real, es decir, que algo pueda ser sometido de forma legítima a la división de lo verdadero y lo falso (Foucault, 2007, p. 37), por ejemplo la locura, la sexualidad, la raza, la delincuencia.

Agamben (2011) rastreó el concepto de dispositivo en el trabajo de Foucault remontándose a la filosofía de Hegel, a partir de allí, definió el dispositivo enfatizando su capacidad de sujeción sobre todas las manifestaciones del sujeto, incluyendo las culturales: el dispositivo es un conjunto hete- 
rogéneo de discursos, instituciones, habilitaciones arquitectónicas, decisiones reglamentarias, leyes, medidas administrativas, enunciados científicos, proposiciones filosóficas, morales, filantrópicas... pero especialmente, es la red que tendemos entre esos elementos. De allí que uno de los aspectos más relevantes del dispositivo, para Agamben, es la capacidad de capturar, modelar, orientar, determinar, controlar y asegurar los gestos, las conductas, las opiniones y los discursos de los seres vivos.

Según lo sostenido por Deleuze en 1990, Foucault habría comprendido el dispositivo como un conjunto de cadenas variables relacionadas entre sí, donde saber-poder-subjetividad ocupan el lugar privilegiado. Otra forma de comprender el dispositivo sería a través de la metáfora de máquinas para hacer ver y para hacer hablar. De esa manera, historizar un dispositivo implica hacer una genealogía del régimen de veridicción (verdad) -o enunciación- que lo sostiene. Por ejemplo, al Foucault historizar el dispositivo "prisión", hace una genealogía del régimen de veridicción conocido como derecho penal, que establece quién es delincuente, qué es delito, cuál es la pena o sanción aplicable, entre otros aspectos.

La filosofía del dispositivo, según Deleuze (1990), tiene por finalidad rechazar la idea moderna de los universales (por ejemplo: Estado, razón, sujeto), en tanto estos no explican nada, sino que es necesario explicar el universal mismo, lo que equivale a encontrar las condiciones de posibilidad del discurso que lo han constituido como universal. Por ejemplo, al referirse al Estado, Foucault propuso cuestionar su carácter universal que lo presenta como una fuente autónoma del poder; el Estado sería el resultado de una tensión permanente, una interminable negociación que institucionaliza y centraliza "las fuentes de financiamiento, las modalidades de inversión, los centros de decisión, las formas y tipos de control, las relaciones entre poderes locales, autoridad central, etc." (Foucault, 2007, p. 96).

Desde la óptica del dispositivo, el derecho se puede tomar como un régimen de veridicción conformado por líneas multiformes, heterogéneas y no necesariamente coherentes, que como múltiples vectores de enunciación -en ocasiones contradic- torios- se entrecruzan para constituir una práctica discursiva. Este régimen de veridicción enuncia con autoridad lo que es verdadero por oposición a lo que es falso, o lo que en algunas teorías que constituyen la práctica discursiva del derecho se traduciría por lo que es justo contra lo que se considera injusto como es posible advertirlo en la teoría de Radbruch (1980); en otras bajo el binomio válido-inválido -O conforme a la norma fundamental (Kelsen, 2003) o regla de reconocimiento (Hart, 2004)-, o vigencia del derecho, como aparece en la teoría realista de Ross (1999).

La relación del derecho con el conjunto saberpoder-subjetivación adquiere un matiz propio en la sociedad conformada por relaciones capitalistas, en tanto la ley deja de ser un instrumento de normación, esto es, aquel destinado a distinguir lo normal de lo anormal, para ser una tecnología de normalización, una táctica más del ejercicio del poder propio del gobierno de la población. En este sentido, el dispositivo crea y conduce a la población en la gubernamentalidad, entendida esta última como la forma de gobierno que opera mediante tácticas $-\mathrm{y}$ no solo mediante leyes (aunque las leyes sean parte de las tácticas)-, cuyo objetivo es conducir la conducta de los sujetos a través de la administración -y no simplemente de la fuerza, aunque no renuncia del todo a ella-, o lo que es igual, mediante la dinamización de los flujos (dejar hacer) y la promoción del deseo (Foucault, 2006, 1999). La población a su turno es una manera de designar el sujeto político propio de la gubernamentalidad, sujeto entendido como especie sobre el cual recae el ejercicio de control para que sea más productivo, rentable y profuso. La población no es solo la sumatoria de personas, sino un dato dependiente de múltiples variables, gobernable allende las prohibiciones y las sanciones -sin que esto signifique renunciar a estas- (Foucault, 2006).

Podemos sostener entonces que en la gubernamentalidad la norma funciona a través de tácticas empleadas para hacer interactuar las diferencias, y no para anularlas, de manera que las atribuciones más desfavorables de la anormalidad terminen asimiladas por las más favorables de esa misma anormalidad. La norma no se limita a crear una ruptura 
entre lo normal y lo anormal, sino precisamente busca generar una continuidad, o para decirlo con Foucault (2006): dispone la posibilidad de un flujo destinado a fines plurales y oportunos, todos ejercidos sobre la población mediante complejos y diversos juegos de poder.

Pero icómo hacer una genealogía de esas líneas de fuerza, visibilidad y enunciación que constituyen las prácticas discursivas jurídicas sobre teletrabajo? Para responder a ese interrogante tendríamos que precisar el potencial de una aproximación genealógica. Foucault (1992) argumentó que la genealogía se ocupa de las meticulosidades y los azares, sin preguntarse por el origen de las cosas; se cuestiona por las marcas sub-individuales, singulares, sutiles. Al hacer una genealogía de las prácticas discursivas jurídicas sobre el teletrabajo, emerge la pregunta por las marcas que estas dejan en el sujeto, la manera como se constituye el rol, el estereotipo del teletrabajador. Ahora bien, si la genealogía implica historizar la norma como práctica discursiva por la cual se intenta gobernar la población, icómo abordar entonces ese objeto de estudio que es la ley?

Será preciso aclarar que la genealogía es una herramienta para asomarse al pasado, indagando por las relaciones de poder subyacentes a cosas y fenómenos sin preguntarse por ninguno de estos en sí mismos o por algo así como su esencia o su naturaleza. Mediante la genealogía Foucault renunció a analizar en sí mismas y por sí mismas la naturaleza, la estructura y las funciones de las cosas o los fenómenos, y en su lugar pensar en las diversas maneras como se construyen múltiples relaciones; no podría ser una historia de las ideas, sino de las prácticas cotidianas mediante las cuales estas se construyen. La genealogía busca partir de las prácticas tal como se presentan, pero a la vez, tal como se reflejan y se racionalizan "para ver sobre esa base, cómo pueden constituirse en los hechos unas cuantas cosas sobre cuyo estatus habrá de interrogarse" (Foucault, 2007, pp. 17-18).

La genealogía, como forma de la crítica (Foucault 1999), permite cartografiar las subjetividades, al preguntarse por cómo es que hemos llegado a ser lo que somos (Foucault 1988): teletrabajadores, consumidores, cibernautas... qué prácticas concre- tas constituyen nuestros roles en la sociedad, antes que preguntar por lo que somos (o la identidad considerada como una entidad en sí misma, inmutable "objeto" de estudio), teniendo en cuenta que la construcción de la subjetividad es un proceso marcado por luchas constantes y no un epifenómeno. Ahora bien, rastrear los mecanismos de sujeción que han construido la subjetividad del teletrabajador, implica preguntarse por la materialización de los dispositivos en diversos momentos de la historia del trabajo y las relaciones que lo constituyen; esto a su vez implica preguntarse por las prácticas concretas constituidas por los discursos.

Una genealogía de las prácticas discursivas jurídicas mediante las cuales se construyen las subjetividades laborales implica cuestionar la manera cómo funcionan los dispositivos por los cuales las relaciones de poder, entendidas como relaciones de dominación pero también de fuga, participan en la construcción de la subjetividad; dispositivo que se rige por la relación entre saber y poder, subyacente tanto a las prácticas como a los discursos. Interesan entonces las prácticas por las cuales las relaciones de poder se entrecruzan en la producción normativa y la manera como estas normas, constituyéndose en mecanismos de sujeción, perfilan la subjetividad del trabajador del ciberespacio; de ese grupo al que con Huws (2003) podríamos denominar los cybertariat.

\section{El teletrabajo}

La ley 1221 de 2008 en Colombia sobre teletrabajo se presentó como mecanismo para incluir a personas tradicionalmente marginadas del trabajo: madres cabeza de familia, discapacitados, habitantes de zonas alejadas de los centros industriales. Este tipo de argumentación no es nuevo ni exclusivo de Colombia. Ochoa (s. f.) sostiene que en Europa el teletrabajo es un factor para equilibrar regiones rurales caracterizadas por flujos migratorios constantes, de manera que sea posible incentivar a sus habitantes a quedarse en su territorio y abstenerse de migrar hacia los centros más poblados. Sin embargo, en Colombia este objetivo está en vilo, dado que la conectividad a Internet es fuertemente inequitativa (a 2011 más del 80 \% de los hogares de 
estratos 5 y 6 contaban con conexión a Internet, en tanto que disponían de ese servicio tan solo el $2 \%$ de los hogares de estrato 1 y el $8 \%$ en el estrato 2 ) y concentrada en las cabeceras urbanas (a 201157.4 $\%$ de las conexiones de Internet estaban en Bogotá, Medellín, Barranquilla, Cali y Bucaramanga), como muestra Orduz (2011).

Se propone en este trabajo buscar las motivaciones de la ley allende la retórica que la motiva, con base en Foucault: poner en evidencia las relaciones de poder que en sociedades como la nuestra funcionan en virtud de la producción y circulación de los discursos constitutivos de "verdades", como el derecho y la psicología. La hipótesis: la intención de la ley es constituir una subjetividad, la de teletrabajador, para hacer interactuar las diferentes formas de trabajo de manera que los aspectos más desfavorables de una situación atípica (anormalidad) -como ciertas formas de organización del trabajo a través de medios electrónicos- terminen asimiladas por los aspectos más favorables de esa misma anormalidad.

¿Cómo y para qué sucede esto? La norma legal por sí sola no crea la subjetividad, lo hace con apoyo de tácticas, otros discursos de verdad -como el discurso de la subjetividad proveniente de la psicología organizacional, pero también de otros discursos que circulan sobre el teletrabajo-, y otras prácticas de intervención sobre la población (como la política estatal) para mover flujos de desempleados al teletrabajo. Al respecto es voluptuosa la campaña del Ministerio de Trabajo para promover el teletrabajo a través de creación de entidades, expedición de documentos institucionales, realización de foros, financiación de campañas de publicidad, beneficios para las empresas que adopten formas de teletrabajo, guías de implementación de teletrabajo, entre otras. Toda esta información además se hace pública y se divulga profusamente a través de la página electrónica del Ministerio de Trabajo.

¿Cómo se hacen interactuar las diferencias en el teletrabajo y qué papel juega la ley 1221? Para algunos autores el trabajo deslocalizado realizado mediante las TIC genera mejores oportunidades e inclusión (Sotomayor \& De la Fuente, 2009), para otros es un resultado inevitable de las nuevas formas de or- ganización del trabajo (Aldao, 2010). Sin embargo, la mayoría (Campbell, 2001; Castillo, 2007, 2009; Hernández, 2009; Huws, 2003; Lenguita, 2009; Míguez, 2008; Thibault, 2000), argumentan que el teletrabajo ha contribuido a flexibilizar las relaciones laborales, aumentar el aislamiento del trabajador, incrementar las jornadas de trabajo, abaratar los costos de trabajo a favor de las empresas y en detrimento del patrimonio del trabajador, aumentar la incertidumbre en materia de riesgos laborales, atomizar la organización de los trabajadores, disminuir la autonomía haciendo que la subordinación devenga en telesubordinación, romper la frontera entre lo público del trabajo y lo privado del hogar, entre otros aspectos desfavorables para el trabajador. Con semejante panorama iqué trabajador desearía insertarse en estas formas de trabajo precarias? Para un ejercicio del poder centrado en la rentabilidad de los cuerpos es necesario hacer interactuar estas anormalidades de manera que resulten favorables. Uno de los mecanismos para hacerlo se instala en el espacio micro-físico del poder, en el cuerpo del trabajador, en la formación de la subjetividad, de tal manera que la persona no simplemente acepte la precarización del trabajo, sino que anhele teletrabajar, aun en condiciones precarias.

Con Foucault (2007), leyes como la 1221 pretenden resolver las contradicciones, o lo que él denominó, los efectos de callejón sin salida de la sociedad capitalista; en el caso de análisis: las actuales formas cibernéticas de organización del trabajo en las que -como argumentan diversos autores (Braverman, 1974; Huws, 2003) predomina la producción de servicios informáticos, de seguridad y de control de las mentes- se reproducen y se profundizan las contradicciones propias del trabajo capitalista, las cuales nunca terminan de resolverse. No obstante, el derecho -especialmente en su versión más liberal- atribuye las contradicciones a una figura precisa y particular del complejo económico jurídico de relaciones generadas por las formas de producción y distribución capitalistas: la repartición de la riqueza vía salarios, puestos de trabajo, capacidad de consumo, etc.

A través de la ley 1221 de 2008 vemos al derecho actuando como régimen de veridicción que da 
forma a la subjetividad, régimen que hace parte de un dispositivo más grande que podríamos denominar provisionalmente como las formas de gobierno del trabajo en la era de las TIC. La manera como esta compleja red de articulaciones funciona es diversa y multi-localizada: por un lado muestra al teletrabajo como una herramienta para disminuir -literalmente a cualquier precio- el desempleo, ese gran obstáculo para el crecimiento y el desarrollo; pero además para mitigar la pobreza y la exclusión. Por otro lado, hace parecer el trabajo de los call center - una forma de empleo por demás precaria y poco atrayente como muestran Del Bono y Bulloni (2008) y Del Bono (2005), como una forma de teletrabajo-.

Para algunos, quienes trabajan en un call center son teletrabajadores por el simple hecho de utilizar sistemas de comunicación como internet. Por ejemplo, un proyecto de reglamentación de la ley 1221 propuesto por el Departamento Administrativo de la Función Pública, que finalmente no fue aprobado, proponía: "Las disposiciones contenidas en la ley 1221 no plantean aplicación exclusiva al sector privado, de hecho, se ha tenido conocimiento de viviendas de teletrabajo en el SENA y Telecom, a través de la modalidad de call-center" (Departamento Administrativo de la Función Pública, 2008).

Quienes más se benefician de los call center afirman que estos también son teletrabajo. El siguiente fragmento es uno de esos que - con Foucault (1990)- aquí se denominan discursos menores. En la página electrónica de la Corporación Colombia Digital es posible encontrar un blog en el que se puede leer lo siguiente:

¿Ha deseado que los lunes no sean lunes, qué(sic) las mañanas inicien a la hora en que usted prefiere salir de la cama, que no haya tres despertadores sonando desde las cinco de la mañana para evitar que se quede dormido? iHa deseado trabajar desde su casa, una biblioteca, un parque, cumpliendo responsabilidades sin importar el lugar donde se encuentre? iLe gustaría no tener que pasar largas horas en los insoportables trancones que abundan en nuestras ciudades? iEs de los que piensa que en su casa le "rinde" más que en la oficina? Si usted asintió con la cabeza en más de una ocasión, le recomiendo seguir leyendo este artículo y conocer un poco más acerca del Teletrabajo.

Se trata de la oferta del paraíso eterno. Frente al trabajo entendido como domesticación y administración de la vida y del cuerpo, la posibilidad de recobrar el paraíso perdido surge como la necesaria oposición sin la cual, la precarización del trabajo resultaría insoportable. Y paralelo a esto: qué es lo telemediático en este caso sino la consecución de una suerte de bienestar donde el sujeto renuncia precisamente al pensamiento, o a un reducto de este, en el que la reflexión puede revertir el confort propuesto por la cultura telemediática.

Pero ¿qué entiende la CCIT por teletrabajo? "El teletrabajo se fundamenta en tres principios claves: realizar una labor (1), por la cual se recibe un pago (2), haciendo uso de las tecnologías de la Información y de las Comunicaciones - TIC (3) que le evitan la necesidad de presencialidad" (Corporación Colombia Digital, noviembre de 2013).

Una afirmación controvertible. Primero: que se trate de una labor remunerada no la hace teletrabajo, pues toda relación de trabajo o de prestación de servicios genera una obligación de pago. Segundo: "haciendo uso de tecnologías de la información y las comunicaciones"; un radioperador hace uso intensivo de tecnologías de información y comunicaciones, pero eso no lo hace teletrabajador. Tercero: "que le eviten la necesidad de presencialidad"; quien vende productos por catálogo o trabaja a domicilio no se encuentra en las instalaciones de la empresa, y eso no lo convierte en teletrabajador. Quizás resulte preciso señalar que evitar la "presencialidad" es también evitar el contagio, no solo se trata del confort absoluto, sino además de la asepsia total. Es la manifestación de una política del sujeto, un dispositivo que lo aísla para asimilar y normalizar mediante las anormalidades favorables lo que Foucault (2006) denominó las "anormalidades desfavorables".

Para mostrar cómo actúa el dispositivo como mecanismo de normalización, será preciso apro- 
ximarse más a las características del teletrabajo. Un punto de partida puede ser la dogmática construida por la disciplina jurídica al respecto. En un texto publicado en el año 2000, Thibault expone abundantes definiciones de teletrabajo, al cabo de las cuales afirma:

De lo expuesto se deduce la dificultad de dar una definición de teletrabajo. No obstante, y pese a las diferencias del análisis de éstas y casi un centenar más de definiciones de teletrabajo se detrae la existencia de tres elementos comunes a todas ellas: la localización, esto es, el espacio físico en que se desarrolla la actividad se encuentra fuera de la empresa; la utilización de las nuevas tecnologías informáticas y es preciso que se produzca un cambio en la organización y realización del trabajo. Estos requisitos obviamente son interdependientes entre sí, de tal modo que deben darse simultáneamente para que en rigor pueda hablarse de teletrabajo, pues el trabajo a distancia es tan viejo como el Derecho del Trabajo y el trabajo con nuevas TIC's (sic) no es, por supuesto, privativo del teletrabajo". (p. 25)

La definición de teletrabajo hallada en la página de la Corporación Colombia Digital no es lo único que llama la atención. Afirma quien escribe en el blog que ella misma como teletrabajadora se ha visto beneficiada: "me permite compartir más con mi familia, poder hacer cosas personales que antes había olvidado como ir al gimnasio, cocinar, leer, hacer voluntariados sociales; poner en marcha proyectos propios que de otra manera, jamás habría podido contar con el tiempo y la disponibilidad para hacerlo." Aunque eso sea cierto no se puede tomar como regla general. Si bien pareciera que la subordinación -como poder de mando ejercido por el empleador sobre el trabajador- se matiza en el espacio virtual, en la práctica puede ocurrir justamente lo contrario. Al derrumbamiento del panóptico le suceden formas de vigilancia más eficaces, como las redes virtuales de acceso remoto a cualquier ordenador y software que permite saber quién y a qué hora se conectó, cuánta información envió, qué sitios web visitó, a qué hora se desconectó, entre otros aspectos. Control absoluto de gestos y movimientos escondido tras una potente ilusión: la autonomía absoluta del trabajo flexible y deslocalizado emergente tras la crisis de la empresa fordista.

Lo emergente es el elemento teleológico como la forma suprema de sujeción oculto tras la ilusión, la forma y función moderna de la norma. Se trata en este caso no solo de un dispositivo de seguridad -en términos de Foucault-, reviste también la forma de un mecanismo disciplinario destinado a la domesticación y administración de los cuerpos para el acceso y control del tiempo de trabajo. Para decirlo con Foucault (2006), se trata de una herramienta de disciplina que normativiza para luego -como dispositivo de seguridad-normalizar las conductas y los deseos de la población. La manera como domesticación y administración de los cuerpos en el teletrabajo toman forma, es descrita en estos términos por Thibault (2000): "La utilización de nuevas tecnologías puede suponer algunas veces una mayor autonomía del teletrabajador, pero también en numerosos supuestos el nacimiento de un nuevo taylorismo asistido por ordenador" (p. 44).

Pero entonces ipor qué regular una forma de trabajo que no existe en Colombia o que solo existe de manera marginal, como si en realidad se tratara de un fenómeno extendido? Pregunta que no solo en Colombia resulta pertinente, pues como muestra Castells (1999) en Europa hay más gente investigando el teletrabajo que teletrabajadores reales. Ante el advenimiento del escenario propicio para la producción de mercancías inmateriales, y junto a la extensión de las formas de explotación ya conocidas promovidas entre otras por la proliferación de los call-center, se requiere un trabajador convencido de que ahora sí, finalmente, puede ser su propio jefe, dueño de su horario, sin salir de casa y sin la atadura de la subordinación. Para instalar la organización del trabajo que permita el devenir teletrabajador, se requiere una mentalidad, construir la subjetividad, y para ello es preciso la articulación de regímenes de veridicción, como el discurso psicológico y jurídico, que incentiven el afecto por la explotación, pero que recreen en el sujeto la ilusión liberadora del trabajo autónomo. 
Al buscar en la red "teletrabajo" es fácil encontrar este tipo de discursos menores:

Se busca auxiliar SEO, Link Building, importante conocimientos internet, navegación web, un poco de html, programación web sería una excelente aptitud. La modalidad es teletrabajo, se pagarán 600 mil pesos mensuales. Trabajo desde casa, 8-12 am y 2-6 pm Lunes a Viernes (sic). Sábados 9-2 pm (sic). Posibilidad de crecimiento. Importante una actitud abierta para aprender y una visión a largo plazo. Técnicos, Tecnólogos en Sistemas, Programación, Web. Preferiblemente experiencia en SEO. (Accióntrabajo Colombia)

Este tipo de ofertas de teletrabajo abundan. Es el advenimiento del escenario propicio para la intensificación de formas de explotación de mano de obra calificada por empresas multinacionales dedicadas especialmente a sectores que movilizan grandes recursos de capital, como las comunicaciones y la tecnología. Pero estos mecanismos de explotación no serán posibles si las personas no desean previamente teletrabajar, si no incorporan el teletrabajo en sus prácticas, en su subjetividad, como una forma más adecuada de vida productiva.

Es explicable que el gremio de las empresas de informática y telecomunicaciones promueva el teletrabajo. Y no solo porque venderán más computadores, o más suscripciones a Internet, sino porque Colombia es un lugar privilegiado para el crecimiento de empresas de este sector que empleará mano de obra calificada y barata: técnicos, diseñadores, ingenieros, programadores, todos bilingües. Con una ventaja para el empresario: ahorro de recursos en infraestructura y costos operacionales, pues buena parte de esta correrá por cuenta del teletrabajador, sin mencionar la dificultad que tendrá el trabajador al intentar demostrar que un accidente padecido mientras teletrabajaba se trata efectivamente de un accidente laboral.

Para finalizar, es preciso acercarse un poco más al discurso legal. Según la ley, el teletrabajo puede manifestarse de tres formas: autónoma, móvil y suplementaria. La primera contempla personas laborando todo el tiempo fuera de la empresa - en casa, oficina, un centro comercial- y que solo esporádicamente acuden a la empresa. Móvil se refiere a aquellas personas que carecen de un lugar de trabajo fijo y que usan las TIC en dispositivos móviles como herramientas primordiales en el desarrollo de sus actividades. La última regula la situación del sujeto que labora dos o tres días de la semana fuera de la oficina y el resto en ella. Según la definición de Thibault (2000), la tipificación legal de Colombia no corresponde técnicamente a la de teletrabajo, pues el espacio físico en el que se desarrolla no está realmente fuera de la empresa, o lo es solo de manera parcial. Entonces, la ley produce un teletrabajador mediante la ampliación del campo de acción subjetivo del teletrabajo a contrapelo de la definición producida por la misma dogmática jurídica que busca interpretar la ley para garantizar los derechos. Esta es una práctica discursiva que -acompañada de otras prácticas concretas vinculadas a la flexibilización de las relaciones laborales- construyen la subjetividad de los trabajadores en la era del trabajo virtual, una práctica que muestra la manera como actúan los discursos constitutivos de verdades (quién puede ser considerado teletrabajador y quién no), vectores discursivos que no necesariamente son coherentes.

Este tipo de prácticas fueron identificadas por Polanyi (2003) como el derrumbamiento de las instituciones culturales protectoras de la vida en el trabajo. Una de esas instituciones consagradas durante casi un siglo fue la separación entre el espacio público de la empresa y el privado del hogar. Se trataba de la frontera entre la vida laboral y la familiar, o simplemente la vida íntima del trabajador. Esa frontera se desdibuja con el teletrabajo: el trabajo se introduce en el espacio privado colonizando las formas de vida ajenas al ámbito productivo. Quizás la consecuencia más relevante de esto es la relacionada con el tiempo; al no existir frontera entre lo público y lo privado, tampoco la hay entre el tiempo del trabajo y el tiempo personal, del descanso, del afecto, del cuidado de la familia y del estudio.

Esta pauperización es aceptada dócilmente por el teletrabajador mediante la incorporación subjetiva de la mentalidad fundamental para la nueva organización del trabajo: la renuncia a la idea de 
la jornada de trabajo, y de manera consecuente, la renuncia a la remuneración extra por el tiempo laborado más allá de la jornada ordinaria. Esto es lo que produce el dispositivo en tanto actúa mediante producciones discursivas. Al no existir jornada ordinaria, tampoco la extraordinaria, y por ende, desaparece el fundamento de la remuneración adicional: el artículo 6 de la ley 1221 establece que "a los teletrabajadores, dada la naturaleza especial de sus labores no les serán aplicables las disposiciones sobre jornada de trabajo, horas extraordinarias y trabajo nocturno." Los regímenes de veridicción operan mediante enunciados que se contradicen a si mismos: la ley 1221 entra en contradicción con lo previsto en el mismo decreto que la reglamenta, según el cual es deber del empleador promover la igualdad de trato en materia de remuneración entre teletrabajadores y demás trabajadores de la empresa. No obstante, la contradicción es aún mayor si tenemos en cuenta que el mismo decreto ratifica el contenido del artículo $6^{-}$citado. La contradicción de la contradicción.

$\mathrm{Al}$ momento en que se termina de escribir este artículo, la única decisión judicial de relevancia pública sobre teletrabajo, es la Sentencia C-337 de 2011 expedida por la Corte Constitucional. La Corte no se refiere al alcance de la norma contemplada en la ley 1221 sobre jornada de trabajo, únicamente hace alusión a la necesidad de que la protección en materia de seguridad social a favor de los teletrabajadores, también incluye el sistema de subsidio familiar. Será necesario entonces esperar a que la Corte se pronuncie de fondo sobre una eventual inconstitucionalidad de la ley 1221 en lo que a jornada de trabajo se refiere, en tanto amenaza la garantía contemplada internacionalmente (8 horas diarias). Sin embargo, como ya sucedió respecto de la reforma laboral de 2002, no sería extraño que la Corte Constitucional, bastante indulgente con los empresarios, termine avalando también esta ley sobre teletrabajo.

\section{Conclusiones}

La manera como actúan los discursos y las prácticas al interior del dispositivo es sinuosa y compleja. La producción de subjetividades en el trabajo, como seguramente en todas las esferas de la vida, está determinada por diversas formaciones discursivas que se entrecruzan, se entrelazan y atraviesan a las personas en sus diferentes dimensiones. El poder no se encuentra como una emanación de fuerza que va de arriba hacia abajo, sino que circula entre los sujetos y a través de estos de manera insospechada y sutil. Es el poder que actúa a través de los discursos menores, del ciudadano de a pie que opina a través del blog, de la nota de prensa modesta y cotidiana que no ocupa la primera plana, en fin, de las formas mediante las cuales naturalizamos diversos elementos de la vida cotidiana. Pero el poder también actúa a través de discursos institucionales, de las leyes mediante las cuales se sustraen derechos sociales a favor de intereses de grandes multinacionales, de redes de explotación del trabajo que se presentan como salvavidas ante inevitables crisis económicas. Las relaciones de poder y la manera como operan es sinuosa y sutil, compleja y simple a la vez, pero esto también indica que las personas como sujetos tienen poder y no son simplemente sujetados por el poder.

Así como la ley 789 de 2002 prolongó la jornada de trabajo diurno a la franja horaria comprendida entre las seis de la tarde y las diez de la noche, de la misma manera, pero de forma mucho más sofisticada y sutil, la jornada laboral se extiende al espaciotiempo público-privado del hogar, del café internet, del bus, del centro comercial, o de cualquier otro lugar desde el cual el teletrabajador pueda conectarse a la red. La teleología emergente se manifiesta en su función de eliminación de la frontera entre lo público y lo privado, y al hacerlo, transforma en ciudadano -sujeto útil y de consumo-incluso al sujeto improductivo del hogar: el trabajo del dispositivo de seguridad que asimila la anormalidad desfavorable.

En la fase de expansión del capitalismo que actualmente atravesamos, es la producción de ideas, de imágenes, de mercancías virtuales, lo que hace la diferencia frente a las relaciones capitalistas descritas por Polanyi (2003) en La Gran Transformación. Como Harvey (2004) pone de presente, los procesos "coloniales, neocoloniales e imperiales de apropiación de bienes" especialmente inmateriales, continúan en la fase actual del capitalismo. Los distintos mecanismos de acumulación por despo- 
sesión, como el mismo Harvey señala retomando a Marx, se trasladan a campos de acción virtual en los cuales las prácticas y las normas mutan con las innovaciones tecnológicas, siguiendo la única ley que obedece el capital: la de la acumulación incesante. Se trata del mismo enunciado, pero dispuesto a través de un régimen de enunciación novedoso. Las promesas de un mundo más igualitario, de mayor acceso a la información, de conexión permanente y de eliminación de las distancias y las fronteras, quizás sean posibles, pero tal mundo implica una transformación profunda de la subjetividad, aspecto que hará surgir interrogantes que aquí simplemente busqué provocar.

Podría parecer que este artículo busca satanizar la tecnología, pero no podría haber una lectura más reduccionista que esa. No se pretende estigmatizar la tecnología, la cuestión es lo que se hace con ella. Como personas podemos hacer que la tecnología sirva para construir una sociedad más equitativa, justa e incluyente, tenemos la capacidad de agencia para eso si abandonamos la indiferencia y el miedo a la diferencia, a la solidaridad y a un mundo sin privilegios excesivos. Pero también podemos hacer todo lo contrario, atrincherarnos en nuestros privilegios de clase aun sabiendo que tarde o temprano los mecanismos de acumulación por desposesión, siguiendo la única ley que obedece el capital, llamarán a nuestra puerta. La decisión depende de nosotros, esa es nuestra mayor potencia, pero también nuestro mayor riesgo. Parece que por ahora va ganando el miedo y la indiferencia.

\section{Referencias}

Accióntrabajo Colombia. (s. f.). Recuperado el 23 de febrero de 2013, de http://acciontrabajo.com.co/ votEdbdg.html

Agamben, G. (2011). ¿Qué es un dispositivo? Sociológica, 26(73), 249-264.

Aldao, C. (2010). Perspectivas futuras para el trabajo y el empleo. Revista de Trabajo. Nueva Época, 6(8), 223-246.

Braverman, H. (1974). Labour and monopoly capital: The degradation of work in the twentieth century. New York: Monthly Review Press.
Corporación Colombia Digital. (2013, noviembre). [Mensaje en un blog]. Recuperado de http://www. colombiadigital.net/documentos/item/689-enmarcha-hacia-el-teletrabajo.html

Campbell, D. (2001). ¿Puede atajarse la desigualdad en el ámbito de la tecnología digital? Revista Internacional del Trabajo, 120(2), 149-173.

Castells, M. (1999). La era de la información. Economía, sociedad y cultura. Buenos Aires: Siglo XXI.

Castillo, J. (2007). El trabajo fluido en la sociedad de la información: organización y división del trabajo en las fábricas del software. Revista de Trabajo Nueva Época, 4, 125-141.

Castillo, J. (2009). Las fábricas de software en España: organización y división del trabajo. El trabajo fluido en la sociedad de la información [Versión electrónica]. Trabajo y Sociedad, 11(12).

Corte Constitucional de Colombia. Sentencia C-337 de 2011 (M. P. Jorge Ignacio Pretelt Chaljub: mayo 4 de 2011).

Decreto Reglamentario 884 de 2012 [Ministerio de Trabajo]. Por medio del cual se reglamenta la ley 1221 de 2008 y se dictan otras disposiciones. Abril 30 de 2012.

Del Bono, A. (2005, agosto). Innovaciones tecnológicas y organizacionales. Impacto sobre el trabajo y el empleo de jóvenes y mujeres en el sector servicios: la industria de los call centers en Argentina. Trabajo presentado en el Séptimo Congreso Nacional de Estudios del Trabajo, Buenos Aires, Argentina.

Del Bono, A. \& Bulloni, M. (2008). Experiencias laborales juveniles. Los agentes telefónicos de call centers offshore en Argentina [Versión electrónica]. Trabajo y Sociedad, 11(10).

Deleuze, G. (1990). ¿Qué es un dispositivo? En G. Deleuze (Comp.), Michel Foucault, filósofo (pp. 155-163). Barcelona: Gedisa.

Departamento Administrativo de la Función Pública. (2008). Documento técnico del proyecto del decreto reglamentario de la ley 1221de 2008 por el cual se establecen normas para promover y regular el teletrabajo en el sector público. Recuperado el 26 de febrero de 2013, de http://portal.dafp.gov.co/form/formularios.retrive_publicaciones? $\mathrm{no}=1051$

Foucault, M. (1988). El sujeto y el poder. Revista Mexicana de Sociología, 50(3), 3-20. 
Foucault, M. (1992). Nietzsche, la genealogía, la historia. En J. Varela \& F. Álvarez-Uría (Eds. y Trads.), Microfísica del poder (pp. 7-30). Madrid: Las Ediciones de La Piqueta.

Foucault, M. (1999). Estética, ética y hermenéutica. En Obras esenciales (Vol. 3, pp. 363-368). Buenos Aires: Paidós.

Foucault, M. (2000). Defender la sociedad. Curso en el Collège de France: 1975-1976. Buenos Aires: Fondo de Cultura Económica.

Foucault, M. (2006). Seguridad, territorio, población. Curso en el Collège de France: 1977-1978 (1a. ed.). Buenos Aires: Fondo de Cultura Económica.

Foucault, M. (2007). Nacimiento de la biopolítica. Curso en el Collège de France: 1978-1979. Buenos Aires: Fondo de Cultura Económica.

Foucault, M. (2008). Vigilar y castigar. Nacimiento de la prisión. México: Siglo XXI.

Hart, H. L. A. (2004). El concepto de derecho. Buenos Aíres: Abeledo Perrot.

Harvey, D. (2004). El nuevo imperialismo. Madrid: AKAL.

Hernández, J. (2009). Las empresas trasnacionales frente a los derechos humanos: historia de una asimetría normativa. Bilbao: Hegoa y Omal.

Huws, U. (2003). The making of a cybertariat: Virtual work in a real world. New York: Monthly Review Press/The Merlin Press.

Kelsen, H. (2003). Teoría pura del derecho. México. Editorial Porrúa.

Lenguita, P. (2009). Las tecnologías del trabajo según la prensa especializada. El caso del teletrabajo. Trabajo y Sociedad, 11(12), 1-7.

Ley 789 de 2002. Por la cual se dictan normas para apoyar el empleo y ampliar la protección social y se modifican algunos artículos del código sus- tantivo del trabajo. Diciembre 27 de 2002. DO. №45046.

Ley 1221 de 2008. Por la cual se establecen normas para promover y regular el teletrabajo y se dictan otras disposiciones. Julio 16 de 2008. DO. №47052.

Míguez, P. (2008). Las transformaciones recientes de los procesos de trabajo: desde la automatización hasta la revolución informática. Trabajo y Sociedad, 10(11), 1-20.

Ochoa, J. (s. f.). Anotaciones sobre lecturas acerca de teletrabajo [Versión electrónica]. Recuperado el 13 de enero de 2013, de http://cederul.unizar.es/noticias/ sicoderxv/12.pdf

Orduz, R. (2011, 5 de diciembre). Masificación de internet: una necesidad para Colombia. razonpublica. com. Recuperado el 8 de mayo de 2013, de http:// www.razonpublica.com/index.php/econom-y-sociedad-temas-29/2594-masificacion-de-internetuna-necesidad-para-colombia.html

Polanyi, K. (2003). La gran transformación: los orígenes políticos y económicos de nuestro tiempo. México: Fondo de Cultura Económica.

Radbruch, G. (1980). El hombre en el derecho. Buenos Aires: Ediciones Depalma.

Ross, A. (1999). Teoría de las fuentes del derecho. Una contribución a la teoría del derecho positivo sobre la base de investigaciones histórico-dogmáticas. Madrid: Centro de Estudios Políticos y Constitucionales.

Sotomayor, E. \& De La Fuente, Y. (2009). Las tecnologías de la información y la comunicación (TIC) como instrumento de ejercicio de derechos. Tabula Rasa, 10, 359-373.

Thibault, J. (2000). El teletrabajo. Madrid: Centro de Estudios Sociales. 
